days after surgery because the risk of late-onset deep-vein thrombosis remains high even after discharge from hospital. ${ }^{7,8}$ In one study ${ }^{8}$ this was seen to be at the expense of an increased risk of haemorrhage of $5.1 \%$ in the treatment group and $0.9 \%$ in the control group. ${ }^{8}$ This is usually minor, but may result in the formation of haematoma and wound infection.

The National Total Hip Replacement Outcome Study found that pharmacological prophylaxis was used in $88 \%$ of patients having elective hip surgery with low-molecular-weight heparin alone in $50 \%$, unfractionated heparin alone in $21 \%$ and other anticoagulants such as aspirin, warfarin and dextran in $5 \%$. $^{9}$ Mechanical methods such as the foot pump, which has been shown to be as effective as enoxaparin in reducing thromboembolism, but with fewer soft-tissue side-effects, was only used by $5 \%$ of surgeons as the sole method of thromboprophylaxis. ${ }^{10}$

The choice of pharmacological agent is also controversial. We use unfractionated heparin, which has been shown to reduce the incidence of venographically-detected deep-vein thrombosis by $70 \%{ }^{11}$ Generally, this has, however, been superseded by lowmolecular-weight heparin which has been shown to be superior in reducing the incidence of the formation of thrombi and is associated with a lower incidence of HIT (5\% for unfractionated heparin and $1 \%$ for low-molecular-weight heparin). ${ }^{12}$

There is still much debate surrounding the role of pharmacological thromboprophylaxis in THA. Based on current evidence, it cannot be recommended routinely to all patients. The decision as to whether to anticoagulate or not must lie with the operating surgeon who has to weigh up the risks and benefits. Our case demonstrates well a rare but devastating, complication of the use of heparin. There are few reports in the orthopaedic literature describing loss of a leg after the use of heparin in THR. ${ }^{13}$ Greater awareness of HITTS is needed by all surgeons.
No benefits in any form have been received or will be received from a commercial party related directly or indirectly to the subject of this article.

\section{References}

1. Hirsh J, Warkentin TE, Raschke R, et al. Heparin and low-molecularweight heparin: mechanisms of action, pharamacokinetics, dosing considerations, monitoring, efficacy and safety. Chest 1998;114:489-510.

2. Johnson R, Green JR, Charnley J. Pulmonary embolism and its prophylaxis following the Charnley total hip replacement. Clin Orthop 1977;127:123-32.

3. Warwick D, Williams MH, Bannister GC. Death and thromboembolic disease after total hip replacement: a series of 1162 cases with no routine chemical prophylaxis. J Bone Joint Surg [Br] 1995;77-B:6-10.

4. Murray DW, Britton AR, Bulstrode CJK. Thromboprophylaxis and death after total hip replacement. J Bone Joint Surg [Br] 1996;78-B:863-70.

5. Fender D, Harper WM, Thompson JR, Gregg PJ. Mortality and fatal pulmonary embolism after primary total hip replacement: results from a regional hip register. J Bone Joint Surg [Br] 1997;79-B:896-9.

6. Gillespie W, Murray D, Gregg PJ. Warwick D. Risks and benefits of prophylaxis against venous thromboembolism in orthopaedic surgery. $J$ Bone Joint Surg [Br] 2000;82-B:475-9.

7. Planes A, Vochelle N, Darmon JY, et al. Risk of deep venous thrombosis after hospital discharge in patients having undergone total hip replacement: double-blind randomised comparison of enoxaparin versus placebo. The Lancet 1996;348:224-8.

8. Bergqvist D, Benoni G, Bjorgell O, et al. Low-molecular-weight heparin (enoxaparin) as prophylaxis against venous thromboembolism after total hip replacement. $N$ Engl J Med 1996;335:696-700.

9. National Total Hip Replacement Outcome Study. London: Royal College of Surgeons of England and the British Orthopaedic Association, 2000.

10. Warwick D, Harrison J, Glew D, et al. Comparison of the use of a foot pump with the use of low molecular weight heparin for the prevention of deep vein thrombosis after total hip replacement: a prospective, randomized trial. J Bone Joint Surg [Am] 1998;80-A:1158-66.

11. Nurmohamed MT, Rosendaal FR, Buller HR, et al. Low molecular weight heparin versus standard heparin in general and orthopaedic surgery: a metal-analysis. The Lancet 1992;340:152-4.

12. Warkentin TE, Levine MN, Hirsh J, et al. Heparin-induced thrombocytopenia in patients treated with low-molecular-weight heparin or unfractionated heparin. N Engl J Med 1995;332:1330-5.

13. Baird RA, Convery FR. Arterial thromboembolism in patients receiving systemic heparin therapy. J Bone Joint Surg [Am] 1977;59-A:1061-4.

\title{
MERALGIA PARAESTHETICA
}

\section{A complication of a patient-positioning device in total hip replacement}

\author{
J. Kitson, M. J. Ashworth
}

From Torbay Hospital, Torquay, England

W e describe three patients who developed meralgia paraesthetica after the use of a well-padded and carefully-placed patient-positioning device in total hip replacement.

J Bone Joint Surg [Br] 2002;84-B:589-90.

Received 1 April 2001; Accepted after revision 17 August 2001

Meralgia paraesthetica is characterised by altered sensation and pain on the anterolateral aspect of the thigh, corresponding to the distribution of the purely sensory lateral cutaneous nerve of the

J. Kitson, FRCS, Specialist Registrar

M. J. Ashworth, FRCS Orth, Consultant Orthopaedic Surgeon

Department of Orthopaedic Surgery, Torbay Hospital, Lawes Bridge, Torquay, Devon TQ2 7AA, UK.

Correspondence should be sent to Mr M. J. Ashworth.

(C2002 British Editorial Society of Bone and Joint Surgery 0301-620X/02/412338\$2.00 thigh. The clinical syndrome has an established association with pressure on the nerve. We present three cases of meralgia paraesthetica, which occurred as a result of the use of a well-padded and carefully-placed patient-positioning device during total hip replacement.

\section{Case reports}

Case 1. A 56-year-old woman underwent a routine left total hip replacement (THR) in the lateral position using the Hardinge approach under spinal anaesthesia. A patient-positioning system was used, which consisted of three padded bolsters, one for each anterior superior iliac spine and one for the sacrum (Fig. 1). This device was made in the hospital works department. It had been in use for over ten years and was similar in design to commerciallyavailable systems.

Immediately after operation there was bilateral symmetrical sensory loss in the anterolateral aspect of both thighs, but no motor deficit or leg pain. CT of the spine excluded a haematoma 


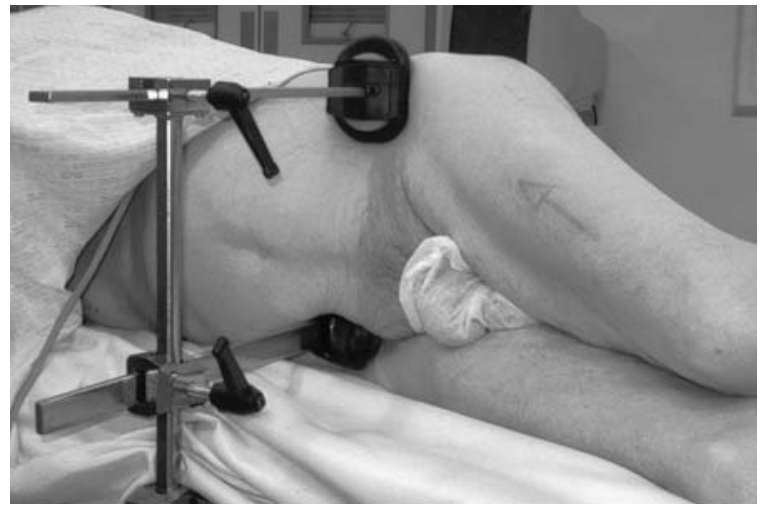

Fig. 1a

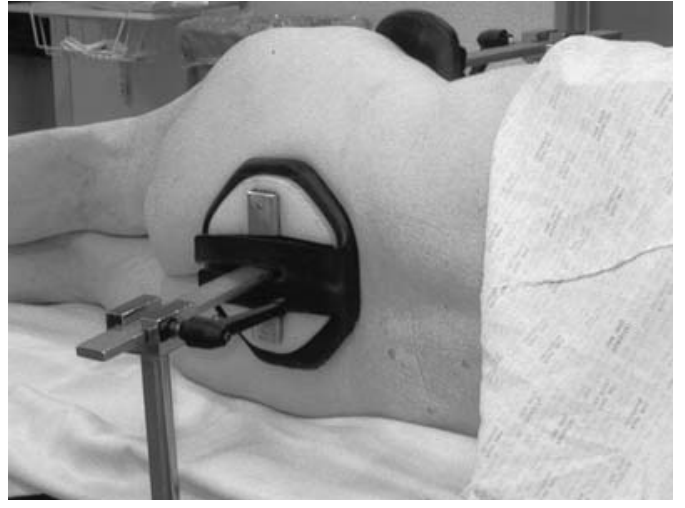

Fig. 1b

The patient-positioning device showing a) the anterior and b) the posterior supports.

related to the spinal anaesthesia as a cause of compression of a nerve root.

Eight days after surgery the left sensory loss had totally resolved and sensation on the right side had significantly improved. At the follow-up at six weeks sensation on the right had fully returned.

Case 2. A 76-year-old woman developed hypoaesthesia, without pain, in the region of the right lateral cutaneous nerve of the thigh immediately after right THR performed using the same supports as in case 1 . The symptoms resolved completely during the course of one week.

Case 3. A 76-year-old man who had sustained an intracapsular fracture of the femoral neck underwent a left bipolar hemiarthroplasty using the Hardinge approach, again using the same supports as in the two previous cases. Immediately after operation bilateral sensory loss was noted, but no pain, in the area corresponding to the lateral cutaneous nerve of the thigh. By the second postoperative day the sensory loss on the left had recovered, and at five days that on the right side had significantly improved. By six weeks the latter had recovered completely.

\section{Discussion}

The use of separate padded supports for each anterior superior iliac spine gives excellent support of the bony pelvis, even in obese patients, when the lateral position is used for hip surgery.

Schumn et $\mathrm{al}^{1}$ reported two cases of injury to the lateral cutaneous nerve of the thigh after THR, although these injuries were not in isolation and were associated with palsy of the femoral and sciatic nerves. The authors suggested that a traction injury had occurred perioperatively. We postulate a different mechanism of injury when the lateral cutaneous nerve of the thigh is affected in isolation.
Initially, we felt that the padded supports had been placed slightly medial to the anterior superior iliac spine to allow easier draping and had resulted in a mechanical neurapraxia of the lateral cutaneous nerve of the thigh. We did not perform nerve-conduction studies in our patients as recovery had occurred before they could be arranged. It is evident from a cadaver study by Murata et $\mathrm{al}^{2}$ that there may be considerable anatomical variation in the course of the nerve. They showed that $39 \%$ of lateral cutaneous nerves of the thigh pass either directly over the anterior superior iliac spine or over the iliac crest within $2 \mathrm{~cm}$ of the iliac spine. In 24 patients with meralgia paraesthetica which had failed to respond to conservative treatment Williams and Trzil $^{3}$ found that the nerve passed up to $4 \mathrm{~cm}$ posterior to the anterior superior iliac spine. Neuromata were present as it passed over the iliac crest.

When a subcutaneous nerve passes over a bony prominence and is subjected to compression, it is at risk of neurapraxia. Thus, some patients will suffer compression of the lateral cutaneous nerve of the thigh even with correct placement of well-padded supports. Full recovery from this previously unreported complication can be expected and is usually complete by six weeks after surgery.

No benefits in any form have been received or will be received from a commercial party related directly or indirectly to the subject of this article.

\section{References}

1. Schumn F, Stohr M, Bauer HL, Eck Th. Peripheral nerve injury due to total replacement of the hip joint. Z Orthop Ihre Grenzgeb 1975;113:1065-9.

2. Murata Y, Takahashi K, Yamagata M, Shimada Y, Moriya H. The anatomy of the lateral femoral cutaneous nerve, with special reference to the harvesting of iliac bone graft. J Bone Joint Surg [Am] 2000;82-A:7467 .

3. Williams PH, Trzil KP. Management of meralgia paresthetica. J Neurosurg 1991;74:76-80. 